\title{
Feeding specializations of the Mexican burrowing toad, Rhinophrynus dorsalis (Anura: Rhinophrynidae)
}

\author{
LINDA TRUEB \\ Department of Systematics and Ecology and the Museum of Natural History, The University \\ of Kansas, Lawrence, Kansas 66045, U.S.A.
}

AND

Carl Gans

Division of Biological Sciences, The University of Michigan, Ann Arbor, Michigan 48109, U.S.A.

\author{
(Accepted 8 June 1982)
}

(With 5 plates and 4 figures in text)

Of the several, unrelated anuran taxa that feed underground, the Neotropical pipoid, Rhinophrynus dorsalis, seems to be the most specialized ant- and termite-feeder. The snout is covered with a curious and apparently unique epidermal armour. The buccal and oesophageal linings are ornately folded. The lips effect a double closure along the long, wedgeshaped, edentate maxillary arch. Peculiar submandibular glands seem to enhance the seal of the lips. The results of morphological, cinematographic, and muscle stimulation studies reveal that Rhinophrynus has a mechanism of tongue protrusion basically distinct from that of other frogs that project their tongues by means of a lingual flip. In Rhinophrynus, the intrinsic tongue muscles act to stiffen the organ, exerting hydrostatic pressure on the fluid contents of the lingual sinus. Actual protrusion of the tongue through the buccal groove involves shifting the organ forward via protraction of the hyoid by muscles extrinsic to the tongue- - a mode that is unique among anurans and one highly suited for securing small insect prey in subterranean burrows.

\section{Contents}

\begin{tabular}{|c|c|c|c|c|c|c|c|c|c|}
\hline & & & & & & & & & Page \\
\hline Introduction & . & . & $\cdots$ & . & . & .. & . & . & 190 \\
\hline Materials and methods & . & .. & . & . & . & .. & .. & .. & 190 \\
\hline Results .. & .. & .. & .. & . & . & . & .. & .. & 191 \\
\hline External morphology & . & .. & .. & .. & .. & .. & .. & . & 191 \\
\hline General body design & 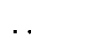 & .. & .. & .. & .. & .. & .. & .. & 192 \\
\hline Features of the cranial anat & tomy & .. & $\ldots$ & .. & . & .. & .. & . & 193 \\
\hline Buccal cavity and topograpl & hy of $t$ & tongue & and 0 & sophagus & $\ldots$ & . & .. & . . & 196 \\
\hline Muscles involved in feeding & & .. & .. & . & .. & . & .. & .. & 200 \\
\hline Discussion & & .. & .. & .. & .. & .. & .. & .. & 202 \\
\hline The habitus of Rhinophrynt & & . & .. & .. & . & . & . & . & 202 \\
\hline Lingual protrusion & .. & .. & .. & .. & .. & .. & .. & .. & 204 \\
\hline Mechanics of the tongue & .. & .. & .. & .. & .. & .. & .. & .. & 205 \\
\hline Evolutionary implications & .. & .. & .. & . & .. & .. & .. & .. & 206 \\
\hline Summary & .. & .. & .. & .. & . & . & .. & . & 207 \\
\hline References & .. & .. & .. & . & . . & .. & .. & . & 208 \\
\hline
\end{tabular}




\section{Introduction}

Descriptions of the mechanism of tongue protrusion in anurans date from before Dugès (1827) and are more prevalent than one might imagine (for a summary of this literature, see Gans \& Gorniak, 1982). With one exception (Regal \& Gans, 1976), these papers are concerned principally with species that protrude their tongues by means of a lingual flip. This, of course, accounts for the majority of taxa in which the tongue is attached anteriorly, free posteriorly, and projected out of the buccal cavity by rotation over the mandibular symphysis. However, as reported by Regal \& Gans (1976), the anatomy of some anuran tongues precludes their protrusion by a lingual flip. The Mexican burrowing toad, Rhinophrynus dorsalis Duméril and Bibron 1841, is one such frog.

Rhinophrynus is one of several, unrelated burrowing frogs specialized for burrowing and eating ants and termites. Rhinophrynus, along with Breviceps (Microhylidae), Hemisus (Ranidae), and Myobatrachus (Myobatrachidae), among others, is characterized by a rotund, distended body, exceedingly short, powerful limbs, pustulose, loose skin, short head, tiny eyes, and the lack of a tympanum. Features of internal and larval morphology of Rhinophrynus clearly differentiate it phylogenetically from all other burrowing anurans and ally this monotypic genus with the aglossal pipids in the suborder Pipoidea, a group of highly derived, primitive frogs (Lynch, 1973; Sokol, 1975, 1977).

Magimel-Pelonnier (1924) briefly described the tongue musculature of Rhinophrynus, and Noble $(1931: 500)$, partly in error, reported that "...the tongue is peculiar in that it is free anteriorly and apparently protrusible in mammal, rather than in frog, fashion." He also noted that Rhinophrynus feed largely on termites, a fact later documented by Kellogg (1932) and Freytag (1967).

In view of the reported peculiarities of Rhinophrynus, the acquisition of some living specimens of the species in 1980 was a bit of serendipitous good luck. It was at that time that a serious investigation of the morphology of this species was undertaken in order to describe the tongue, its mechanism of protrusion, and ancillary anatomical features that seemed to relate either to tongue protrusion or the specialized dietary habits of this species.

\section{Materials and methods}

Descriptive accounts are based on examination of 17 osteological preparations-nine dry and eight cleared and stained specimens representing mature males and females, and juveniles (The University of Kansas Museum of Natural History [KU] 62 137, 69084-85, 70978, 84883-886, 86648, 101952-953, 101956, 187801-802; The University of Michigan Museum of Zoology [UMMZ] S-1806, 152340), one set of serial cross sections prepared by R. Baldauf (KU 186799), and four dissections of adult males and females (KU 70981, 86641, 86647; UMMZ 122076). Preparation of osteological and histological specimens and the methods of recording morphological observations are described in Trueb \& Cannatella (1982). Abbreviations used in figures are included after the first reference to the structure in text. In order to observe disposition of muscle fibres within the tongue, muscles were macerated in $30 \%$ nitric acid to dissolve connective tissue; subsequently, the acid was aspirated and the specimen stained with Toluidine Blue and stored in 50\% glycerol. Scanning electron micrographs were taken on a Jeo1SM-u3 at the Laboratory of Scanning Electronmicroscopy at The University of Michigan.

Although Rhinophrynus occasionally have been observed to feed in captivity (Cannatella, pers. comm.), we were unable to condition them to feed on ants or termites so that we could film the feeding 
sequence. Consequently, our results are based on morphological analysis amplified by muscle stimulation. The animals were first anaesthetized by intraperitoneal injection of $(0.04 \mathrm{mg} / \mathrm{g}$ body weight) of Tricaine Methanesulfonate (MS 222). Stimulation was by bipolar electrodes fashioned from insect pins fixed in Epoxy and driven by a Grass S-6 stimulator at $8 \mathrm{~V}$ and various twitch and tetanic frequencies (and pulse durations).

\section{Results \\ External morphology}

The general habitus of Rhinophrynus has been described briefly in the Introduction and in more detail elsewhere (Walker, 1938; Trueb \& Cannatella, 1982). Certain observations, however, bear comment and elaboration here. Noble (1931: 140) noted that Rhinophrynus has thinner and smoother skin than its "epigean" relatives. We found the skin to be pustulose (Plate I) and loose on all parts of the body except the snout, palmar and plantar surfaces, and the belly wall, where it is attached closely to underlying muscles. Histological preparations reveal the skin to be of normal thickness, but characterized by large numbers of mucous and granular glands. The density of these glands is reminiscent of the unrelated Neotropical genus, Phrynohyas (Hylidae). The skin of the narrow, truncate snout is closely adherent to the underlying skull and elaborated into cushionlike pads, except in the area of the upper lip and the mandibular symphysis. Here, the skin is thick, smooth, and calloused, forming a kind of terminal disc (Plate I). Examination of the skin of the snout by scanning electron microscopy yielded surprising results. Each cell of the free layer is armed with a keratinous spine or spicule. The spines are acuminate on the dorsum of the snout (Plate II(a), (b)) and rounded on its ventral aspect (Plate II(c)). In contrast, other skin surfaces of the animal show no such epidermal modifications (Plate II(d)). To our knowledge, these spines are a unique feature among anurans.
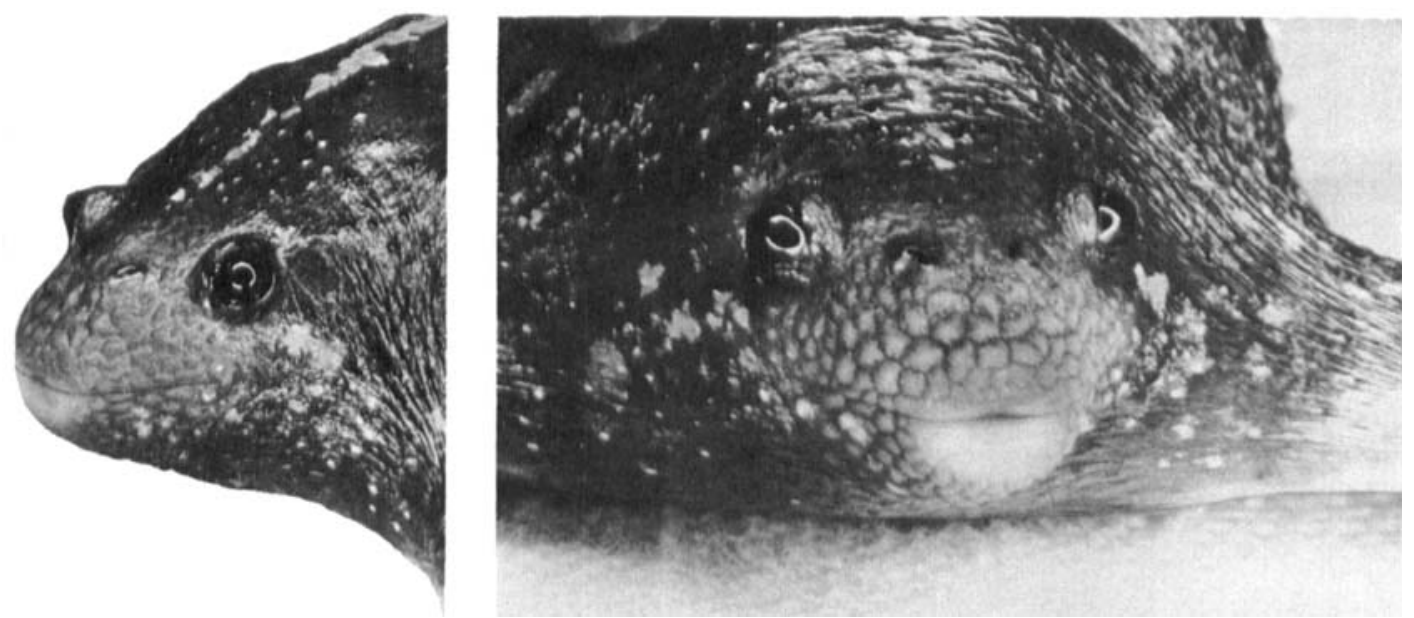

PLATE 1. Rhinophrynus dorsalis. Left. Three-quarter view of head to show proportions of snout, eyes, and nostrils. Note position of shoulder girdle relative to the eye; it surrounds the posterior part of the skull. Right. Frontal view of head to show calloused tip of snout. ( $\times 3$; interocular distance is $8 \mathrm{~mm}$ ). 

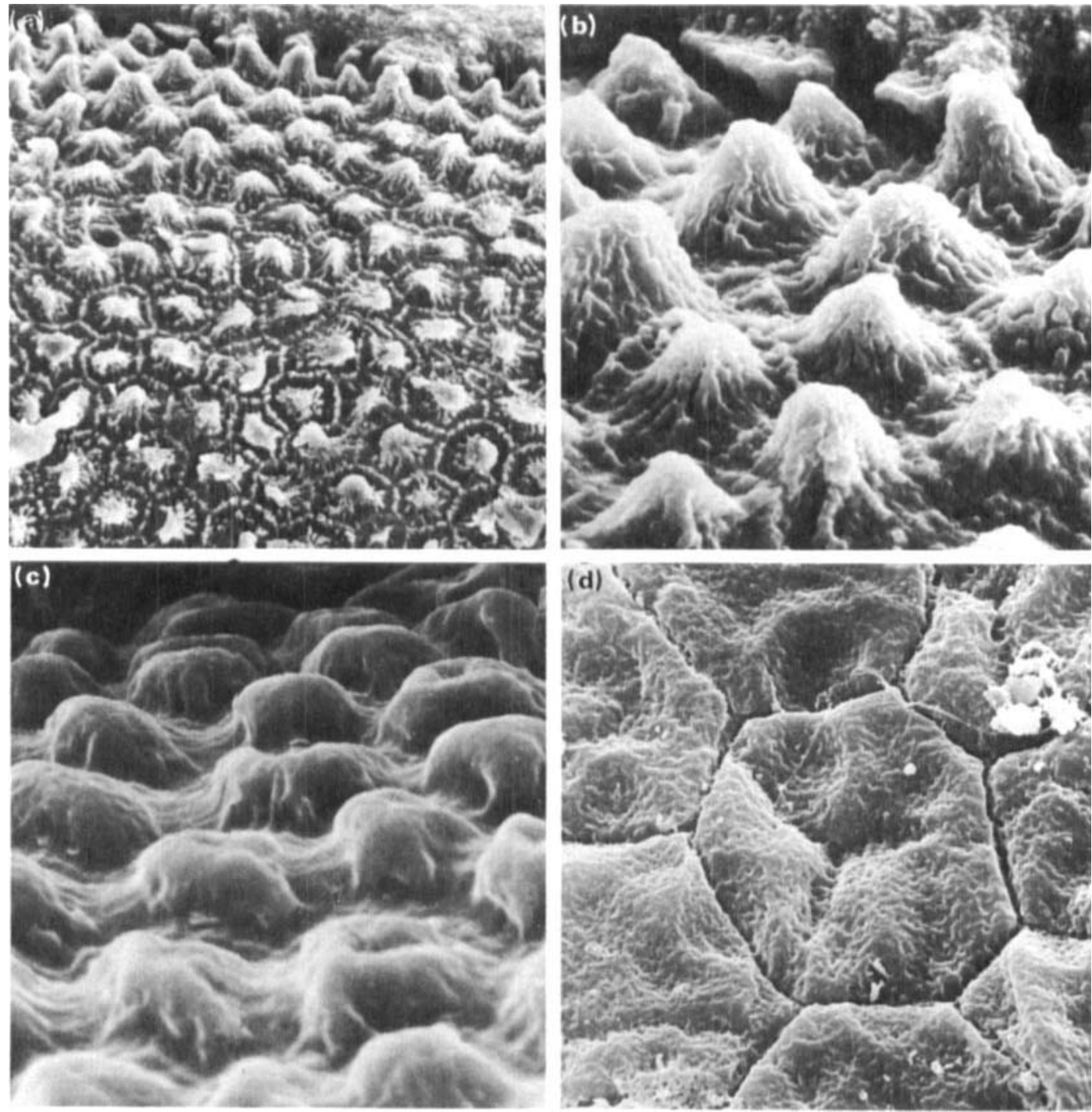

PLATE II. Rhinophrynus dorsalis. Scanning electron micrographs of the integument. (a) View of skin from dorsum of snout to show the surface epithelium, including the keratinized processes extending from each cell. ( $\times$ 505). (b) Detail of (a). $(\times 1275)$. (c) Similar view of skin from ventral surface of the snout. Note the more rounded bosses of the individual keratinized tips. $(x$ 1417). (d) View of the epidermal surface on the belly of the frog demonstrating the absence of any kind of keratinized protrusions. $(\times 1608)$.

\section{General body design}

The body plan of Rhinophrynus is short and squat. The limbs are robust and spatulate; the hind limbs show several modifications and the astragalus and calcaneum are short and fused to one another. Moreover, as reported by Noble (1931: 501; his fig. 27), the prehallux is large and the fifth digit has only a single phalangeal element which is modified into a shovel-like structure. The vertebral column is distinguished by its imbricate vertebrae and 

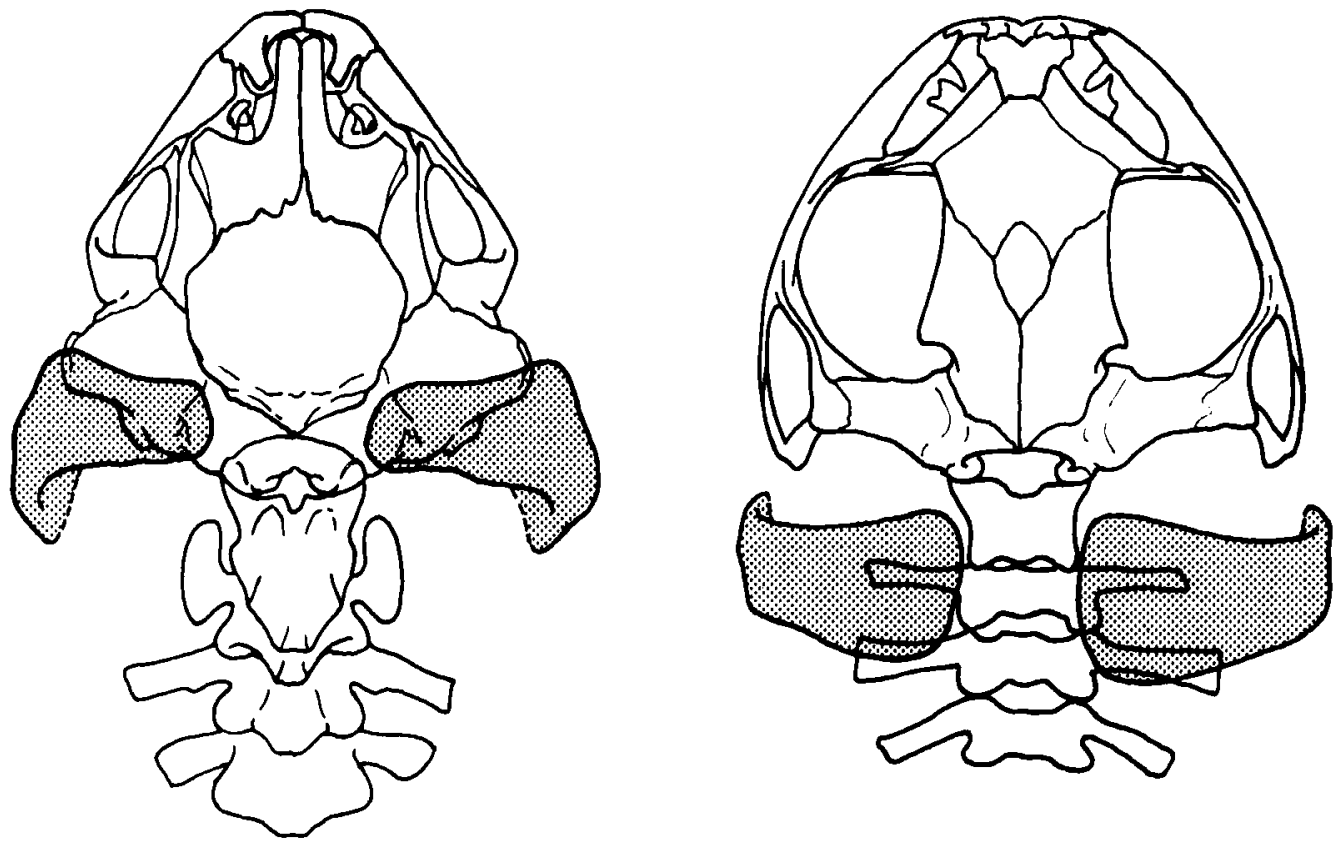

FiG. 1. Dorsal views of skull and pectoral girdle of Rhinophrynus dorsalis (left) compared with those of a more typical frog, the hylid Smilisca baudinii (right). Suprascapulae are stippled.

reduced transverse processes (Fig. 1). The head seems to be recessed into the pectoral girdle when, in fact, the pectoral girdle lies forward of its usual position and encircles the auditory region of the skull-a fact noted by Regal \& Gans (1976). The girdle is stout, having nearly fully ossified suprascapulae, and long, robust scapulae, but it lacks a sternum and has only a rudimentary omosternum.

\section{Features of the cranial anatomy}

A complete description of the cranial osteology and hyolaryngeal apparatus has been described (Trueb \& Cannatella, 1982). It is important to note here that Rhinophrynus is edentate, and that the suspensorium is shifted anterior to the auditory region of the skull so that it lies anterior to, rather than within, the pectoral girdle. In order to accommodate the anterior shift of the mandibular arch, the snout is protracted, and the hyoid plate located in a more forward position (Fig. 2(a), (b)). The entire hyoid plate is foreshortened. As a consequence, anterior processes are absent, the hyoglossal sinus is shallow, and the hyoglossal membrane reduced. The anterior cornua are bipartite and lack an anteroventral loop in Rhinophrynus; however, the hyoid plate is reinforced ventrally by what seems to be a dermal ossification, the parahyoid bone. Cross sections disclose that the skull of Rhinophrynus is deep, and that the buccal cavity is long, narrow, and vaulted in contrast to that of other anurans.

Meckel's cartilage (Fig. 2(a), (c)) is a conspicuous element of the lower jaw. In contrast to the mandibles of most other anurans, those of adult Rhinophrynus do not articulate at the mandibular symphysis, nor are mentomeckelian bones present. Juvenile specimens show 

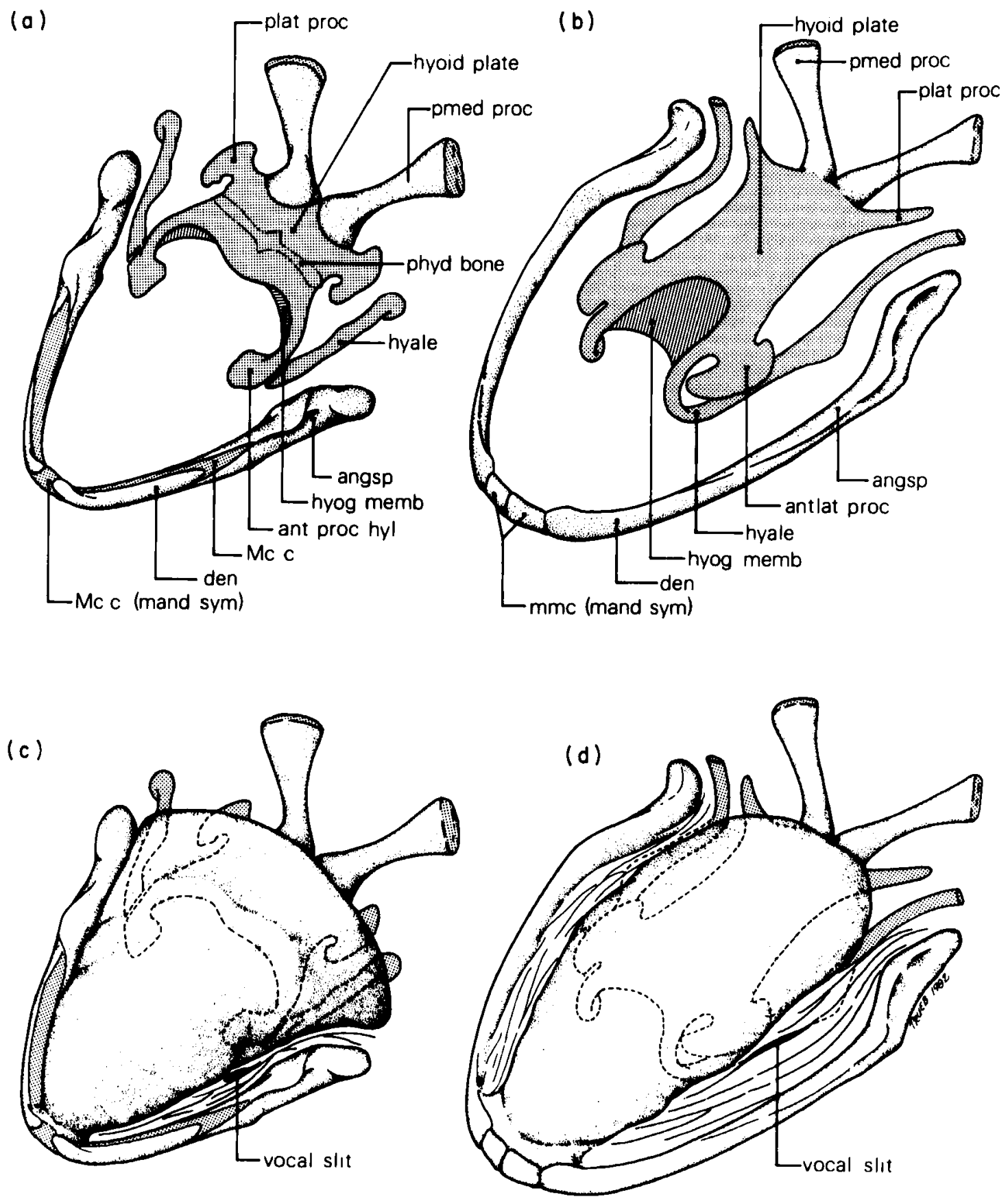

Fig. 2. Isometric views of mandible and hyold (a), (b) and the same views of the tongue in place (c), (d) for Rhinophrynus dorsalis (left) and Bufo marinus (right). 

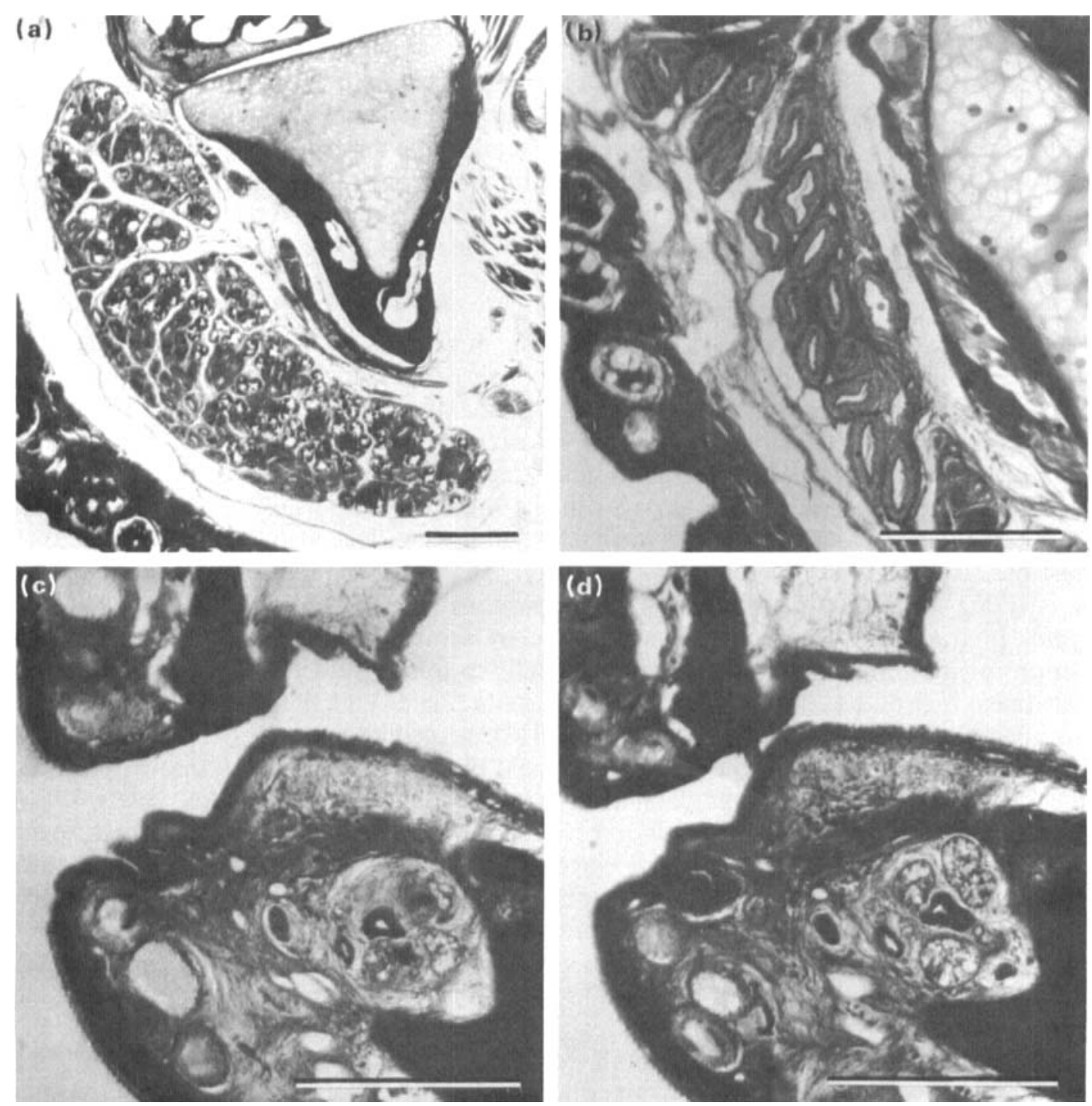

PLATE III. Rhinophrynus dorsalis. Photomicrographs of cross sections of submandibular gland on right side of head. (a) Posterior and largest part of gland at level of jaw articulation. The gland lies ventrolaterally adjacent to the mandible, here represented by the $\mathrm{V}$-shaped angulosplenial enclosing the triangular mass of Meckel's cartilage. Note the two distinct types of cells included in the gland. (b) Anteriorly, at approximately the midlength of the mandible, the gland is shown as a group of tubules extending along the lower jaw just beneath the skin. (c), (d) At the tip of the snout, the tubules emerge along the occlusal margin of the lower lip (c). The tubule and its contents can be seen in (d). The gland lies medially adjacent to the dentary. Note the conformation of the upper and lower lips. Scale $=0.5 \mathrm{~mm}$. 
an articulation; however, chondrification and the development of dense connective tissue posterior to the symphysial region gradually obliterates the medial articulation of the mandibles (Plate IV(a), (b)). The dentary is a thin, delicate bone applied to the lateral aspect of Meckel's cartilage and completely surrounds it in the region of the jaw articulation. A large, conspicuous glandular mass lies ventrolateral to the angulosplenial and fills a lateral groove in the fold of the dentary (Plate III(a), (b), and cf. figs 1, 3 in Tyler, 1974). Tubules from this gland extend forward along the margin of the dentary and open onto the surface of the skin and along the lips near the terminus of the snout (Plate III(c), (d)).

\section{Buccal cavity and topography of tongue and oesophagus}

The buccal cavity is deep and narrow. The wide dorsal and ventral lips effect a congruent, platelike closure anteriorly (Plate III(c), (d)), which is interrupted dorsomedially (Plates I, IV(a), (b)) by a small groove that leads to the premaxillary sinus and thence to the buccal cavity proper. Most of the lining of the buccal cavity is composed of smooth cuboidal epithelium. However, the roof of the mouth bears mesa-like epithelial projections (Plate V(a)) that coincide with deep, parallel grooves in the middorsal region of the buccal cavity. In a relaxed state, the large tongue is triangular in dorsal view, deep and rounded, and occupies most of the floor of the buccal cavity (Fig. 2(c)). The tongue contains an extensive lingual sinus (Plate IV(c)-(h)), and Fig. 2 shows its position relative to the mandibular arch and hyoid. In the slightly contracted state shown by some preserved specimens, the lateral margins of the tongue have rolled ventromedially to fold inward towards the lingual base, and appear in profile as does the head of a mushroom (Plate IV(e), (f)). The slight dorsomedial protuberance evident in Plate IV(e) gives way to a deep median sulcus posteriorly (Plate IV(f), (g)). The anterior margin of the underlying hyoid plate is marked by a shallow, transverse sulcus (Fig. 2(c)); posterior and lateral to this margin, the tongue is free (Plate IV(h)). The dorsal surface of the tongue bears deep, fungiform processes (similar to those of the oesophagus; cf. Plate V(b), (c)); deep glands empty onto the surface of the tongue between these processes. Only the dorsal surface of the tongue is glandular; the sides and ventral surfaces are covered with smooth, cuboidal epithelium.

As the oesophagus is approached one notes that its luminal walls are folded, with these thin walls which are coincident with the anterior projections, extending medially to contact each other at the centre of the oesophageal lumen (Plate V(d), (e)). Each fold consists of a sheet of connective tissue covered on both sides by a cuboidal epithelium containing numerous goblet cells apparently filled with mucous secretion. The sheets show no direct indication of a capillary supply, nor are there larger vessels.

PLATE IV. Rhinophrynus dorsalis. Photomicrographs of cross sections of the tip of the snout and tongue. The approximate locations of the sections are shown on the inset. (a), (b) Tip of the snout anterior to the tongue. Note the buccal groove (a) and the narrow, vaulted buccal cavity (b). The solid, cartilaginous mandibular symphysis is shown in both sections. (c) The anterior tip of the tongue showing mixed genioglossal and hyoglossal fibres underlain by the paired $\mathrm{Mm}$. geniohyoideus and intermandibularis. (d) Slightly posterior, the paired, medial bundles of hyoglossal fibres are evident. The muscles flanking the base of the tongue and the transverse fibres forming its floor are also hyoglossal. (e) Section showing the pedestal-like shape of the tongue. Cartilaginous structures are the hyalae. (f) Posteriorly, the deep median sulcus is evident. (g) At the anterior margin of the hyoid plate, part of the M. hyoglossus courses dorsally and posteriorly over the margin to form the posterior part of the tongue. These are shown here as the diagonally oriented muscle fibres. The medial bundles of fibres are the central fibres of the $M$. hyoglossus that extend anteriorly. (h) The posterior margin of the tongue. The broad, V-shaped cartilaginous structure is the corpus of the hyoid. In sections $(c)-(h)$, note the extensive lingual sinus. Scale $=1.0 \mathrm{~mm}$. 

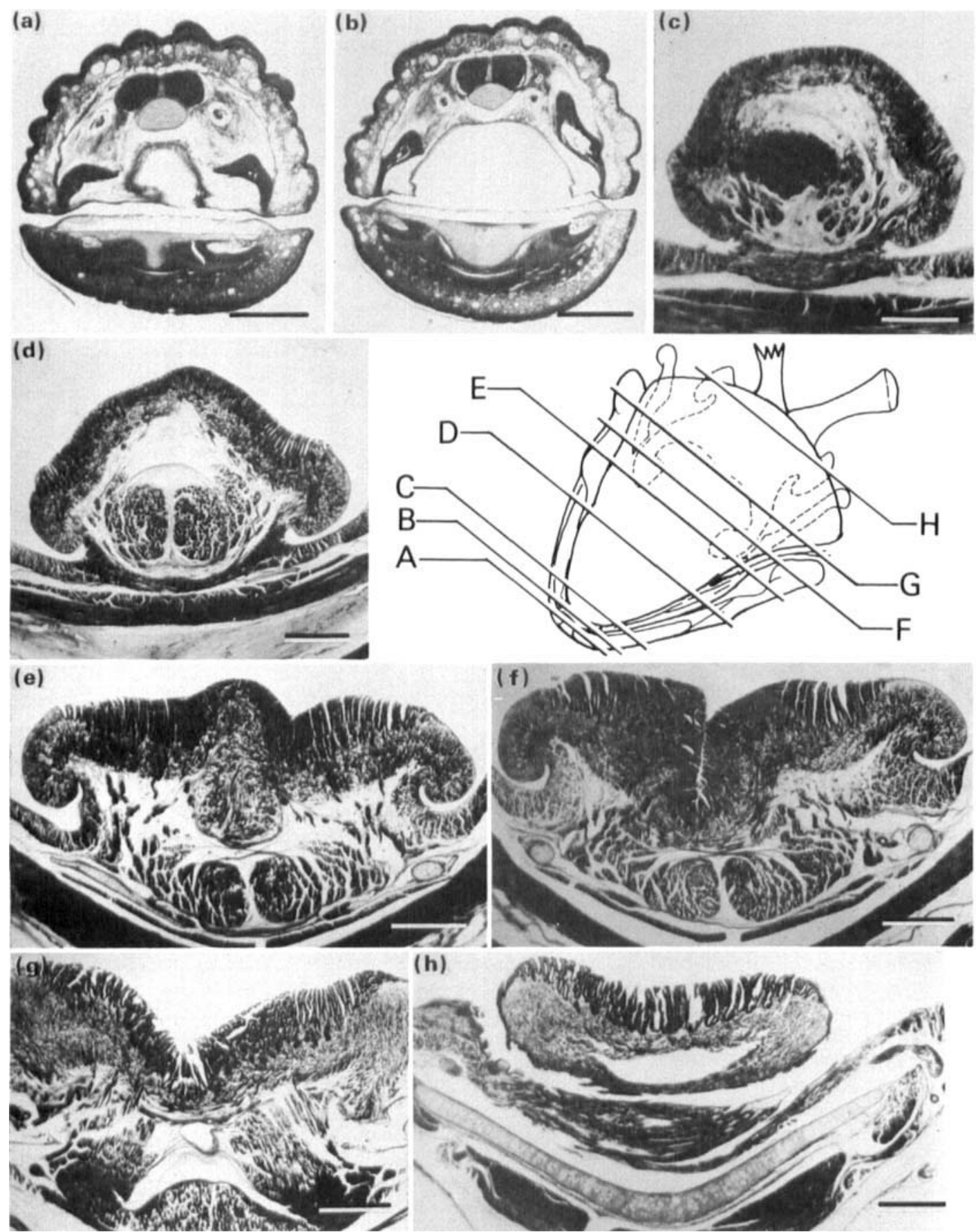

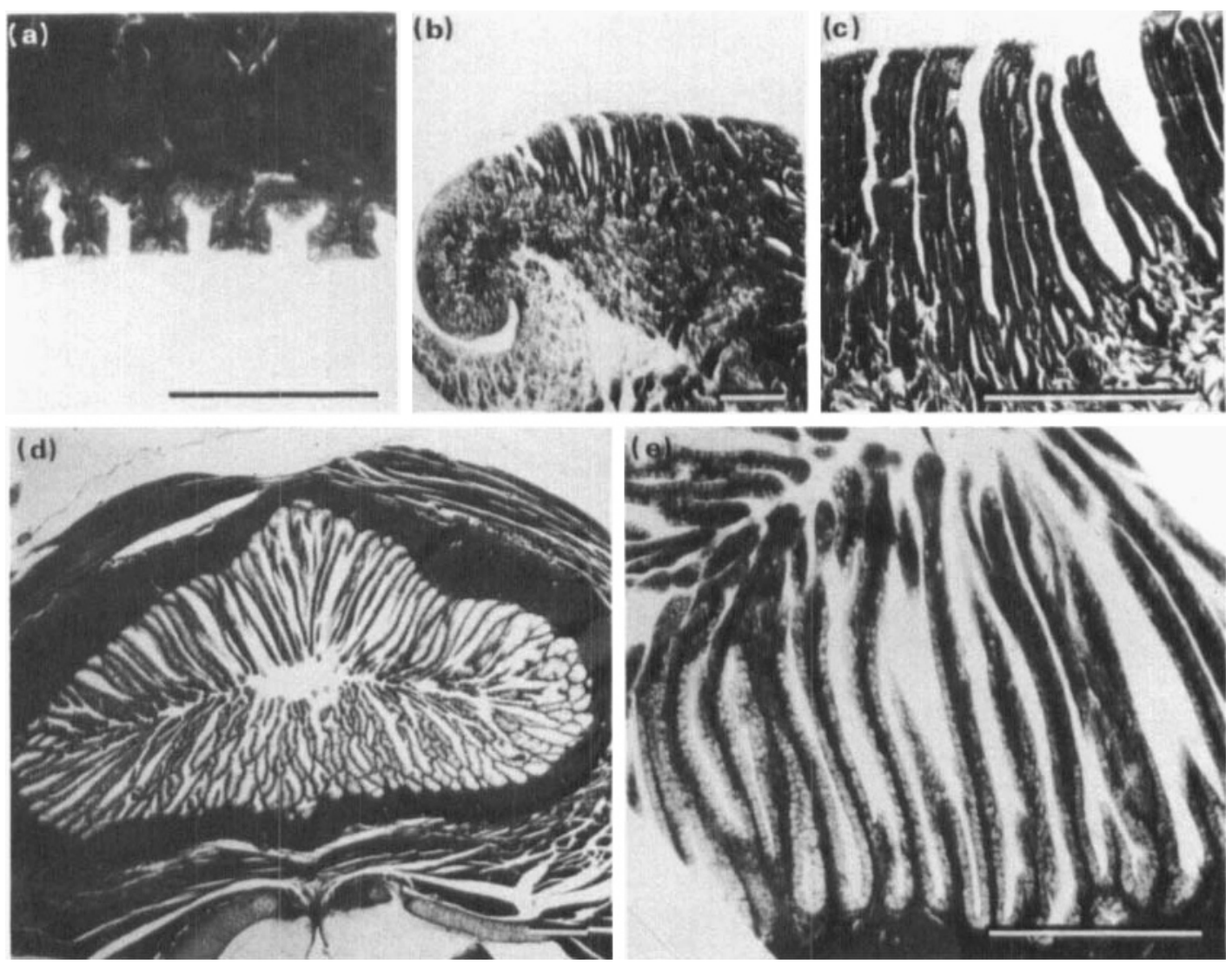

PLATE V. Rhinophrynus dorsalis. Details of structure of buccal lining, tongue, and oesophagus. (a) Mesa-like epithelial configuration of roof of buccal cavity. (b) Surface of tongue showing glandular, villus portion medially that grades to simple cuboidal epithelium laterally. (c) Enlargement of villous lingual surface. (d) Oesophagus, showing complex, plate like folding of lining. (e) Enlargement of oesophageal lining. Scale $=0.5 \mathrm{~mm}$.

Fig. 3. Rhinophrynus dorsalis. Dissections of muscle shown in ventral views for successive layers. (a) (left) Superficial view to show the $\mathrm{Mm}$. intermandibularis and contiguous interhyoideus. The shaded zone represents the two levels of connective tissues, the anterior one reaching from mandible to mandible. The deeper one, shown more posteriorly unites the ventral surfaces of the two slips of the $M$. mentomandibularis. The connective tissues have been shown removed on the right hand side of the drawing disclosing the transverse and continuous $\mathrm{M}$. submentalis anteriorly and the diagonally placed $\mathrm{M}$. mentomandibularis posterolaterally. Note that the latter muscle originates from the bony splint of the submandibular process of the angulosplenial. Note that the posterior transverse muscles are paired and the lateral portions join each other along the very inconspicuous midventral raphe. (b) Diagram to show the two major muscles of the layer disclosed after removal of the $\mathrm{Mm}$. intermandibularis and interhyoideus. Note that the M. geniohyoideus is single and consists of an array of subparallel fibres and overlies (in this view) much of the anterior attachment of the $M$. sternohyoideus, shown exposed on the right hand side of the drawing. Unlike those of most other frogs, these muscles of Rhinophrynus do not interdigitate, i.e., there is only a single rather an overlapping pair of geniohyoids. The dashed line indicates the outline of the tongue. (c) The muscles connecting the hyoid with the skull and shoulder girdle. Note the three distinct slips of the M. petrohyoideus (two shown on the right and one on the left side) as well as the stout $\mathrm{M}$. sternohyoideus that lies ventrad. This muscle is in a better mechanical position to effect anteroposterior movement and its mass appears to be equivalent to that of the petrohyoids. (d) The complex muscles that enter into the composition of the tongue consist of the relatively small $M$. genioglossus and the enormous $M$. hyoglossus. The fibres of the $M$. genioglossus actually consist of two 
(a)
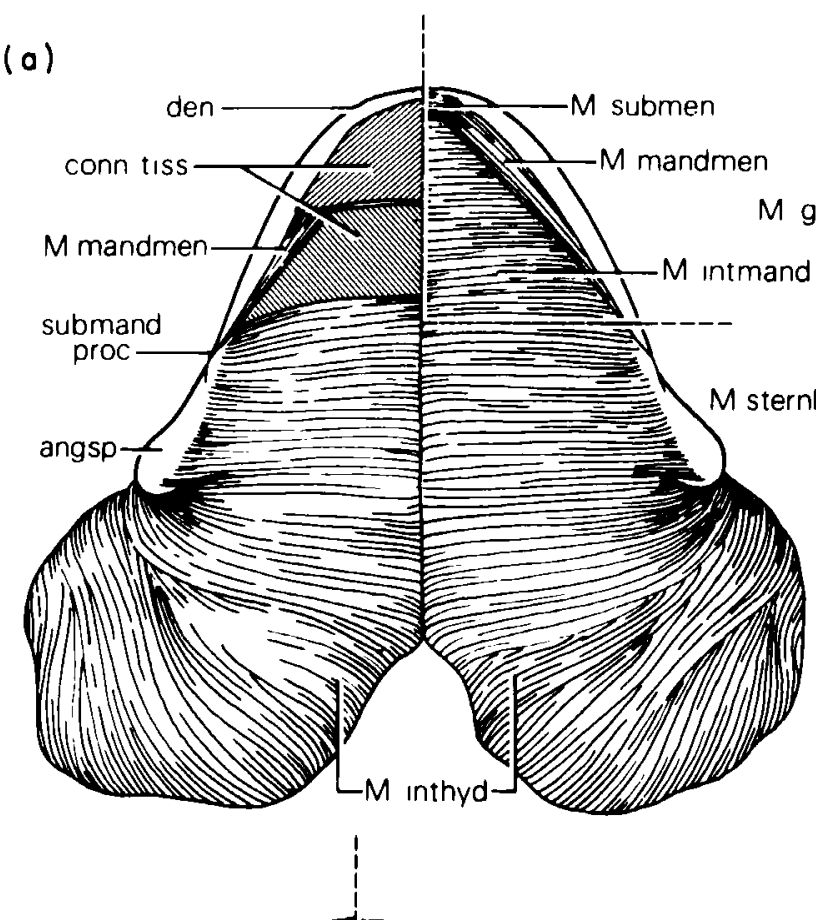

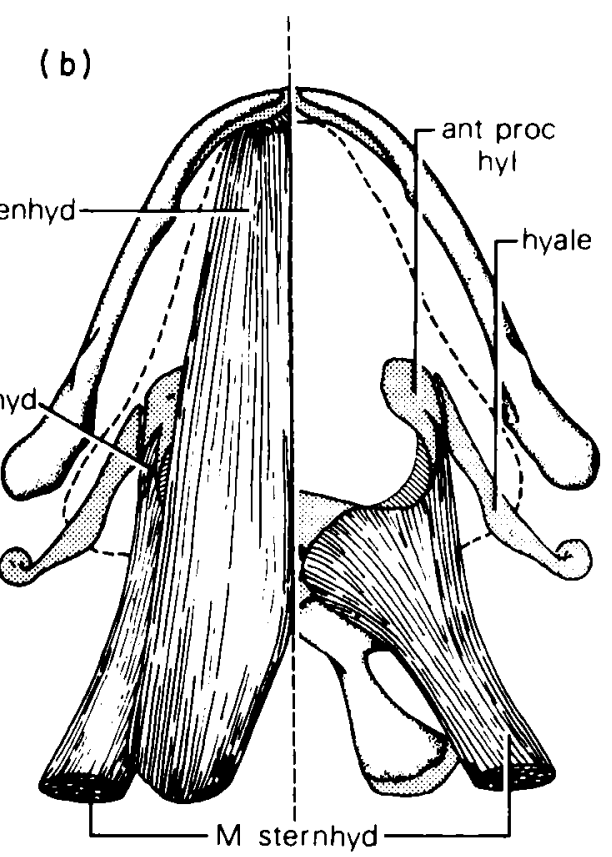

(c) 
Muscles involved in feeding

M. submentalis (Fig. 3(a)).- - On the basis of observations made from dissections, Tyler (1974: 314) suggested that the M. submentalis (M submen) might be absent in Rhinophrynus because (1) "Those muscle fibers present in this region do not form the ovoid body customary in anuran ...", and (2) "... there is no differentiation between these fibers and the flat sheet of the M. intermandibularis posterior to it". Tyler also observed that the connective tissue in the region of the symphysis is thick. Examination of serial cross sections confirms the presence of fibres of the $M$. submentalis in this block of dense connective tissue ventral and posteroventral to the mandibular symphysis-a condition that is not obvious by gross dissection. The fibres of the M. submentalis are organized loosely within their connective tissue matrix and transversely oriented. Unlike those of the $\mathrm{Mm}$. intermandibularis (posterior) and interhyoideus the fibres, of the $\mathrm{M}$. submentalis $(=\mathrm{M}$. intermandibularis anterior) pass continuously between the rami. They are not interrupted by a medial raphe.

The M. submentalis is thickest anteriorly and ventral to the symphysis, where it forms a protuberant bundle. Slightly posterior to the symphysis, the muscle is broader and thinner, and loosely attached laterally to Meckel's cartilage and the dentary via connective tissues. At its posterolateral extremities, fibres of the $M$. submentalis are integrated with those of the $M$. mandibulomentalis, but distinct from the sheetlike $\mathbf{M}$. intermandibularis that lies posterior to the M. submentalis. Stimulation of the M. submentalis appeared to stiffen the floor of the symphysial region.

M. mandibulomentalis (Fig. 3(a)).-The slim M. mandibulomentalis ( $\mathrm{M}$ mandmen) (Tyler, 1974) is unique to Rhinophrynus. It originates via a tendon from the ventral margin of the angulosplenial (angsp), and extends anteriorly along the ventromedial margin of the mandible (mand), becoming progressively compressed and expanded medially. The $\mathrm{Mm}$. mandibulomentalis of the two sides are connected to each other by a thick band of medial connective tissue (conn tiss). The M. mandibulomentalis inserts in the connective tissuemuscle complex of the $M$. submentalis along the posterolateral margin of the latter. Tyler noted that the $\mathrm{M}$. mandibulomentalis originates as the submandibular process (submand proc), a small ventral protrusion located about two-thirds the distance posterior on the mandible. The sections show that the M. mandibulomentalis originates from a small, ventral splint of bone that grades into the angulosplenial from the submandibular process. When stimulated, the M. mandibulomentalis lifts and tenses the tissues on the floor of the mouth.

$\mathrm{Mm}$. intermandibularis and interhyoideus (Fig. 3(a)).-The Mm. intermandibularis (M intmand) and interhyoideus ( $M$ inthyd) appear to be indistinguishable except for gross regional differentiation; hence, they are treated as a unit herein. The anterior portion, located between the mandibles, clearly is the $M$. intermandibularis. Anterior to the submandibular process, the $M$. intermandibularis is associated with the medial margins of the M. mandibulomentalis and comes to lie dorsal to the broad connective tissue raphe connecting this pair of muscles on the two sides. More anteriorly, the $\mathrm{M}$. intermandibularis originates from connective tissue associated with the angulosplenial from its posterior terminus anterior to the submandibular process. Medially, the $\mathrm{Mm}$. intermandibularis inserts on connective tissue posterior to the $M$. submentalis. The median raphe is barely visible in microscopic sections.

The $M$. interhyoideus is extensive and complex. Although it lacks a distinct boundary versus the $\mathbf{M}$. intermandibularis, the $M$. interhyoideus constitutes the posterior portion of the superficial sheet of mandibular muscles that arises from the auditory region of the skull and 
the squamosal as described by Tyler (1974). The superficial mandibular portion of the muscle is convoluted and thick in both sexes, but especially so in males which possess internal, lateral vocal sacs. The $\mathbf{M}$. interhyoideus inserts medially on the epicoracoid cartilage of the pectoral girdle. The combined intermandibular-interhyoid sheet tenses the floor of the mouth.

M. geniohyoideus (Fig. 3(b))-In contrast to most frogs in which the $\mathbf{M}$. geniohyoideus ( $\mathbf{M}$ genhyd) is separated partly or completely into medial and lateral components, the $\mathbf{M}$. geniohyoideus of Rhinophrynus is a single, broad, thin strap of longitudinal muscle fibres that lie superior to the $M$. intermandibularis. Posteriorly, this muscle attaches to the fascia surrounding the distal cartilaginous end of the posteromedial process (pmed proc) of the hyoid. Lateral fibres are straight, whereas medial fibres curve so that the muscles of the two sides meet in the midline at the level of the posterior margin of the hyoid plate. Anterior to this level, the muscles are separated only narrowly throughout their lengths. At its anterior terminus, the M. geniohyoideus attaches to the connective tissues posterior to the mandibular symphysis and between the M. submentalis (inferior) and the M. genioglossus (superior). Stimulation of the strap protrudes the hyoid plate.

M. genioglossus (Fig. 3(d)).-The M. genioglossus (M genglos) is a short, complex muscle that forms the anterior end of the tongue. In some anurans (cf. Gaupp, 1896; Gans \& Gorniak, 1982), two parts can be distinguished-a basal rod that unites the tips of the mandibles and a medial mass that, together with its fascicles, forms the anterodorsal part of the tongue. The M. genioglossus of Rhinophrynus lacks a basal portion. Instead, it is composed of a superficial strap of longitudinal fibres that extends from its connective tissue origin posterior to the mandibular symphysis into the body of the tongue. The anterior end of the "strap" is overlain by a thick sheet of dense connective tissues that connect the mandibles firmly to one another. Posterior to this zone, lateral genioglossal fibres are diverted medially and dorsomedially to form a discrete medial mass of genioglossal muscles that lie dorsal to the straplike portions composed of longitudinal fibres. The fibres composing the medial genioglossal muscle mass turn posteriorly to form a central rod of longitudinal fibres. At the level of the tongue, the lateral and medial components of the $\mathrm{M}$. genioglossus merge. Medial, longitudinal fibres are diverted dorsally to form the anterior tip of the tongue. Posteriorly, medial fibres merge in a transverse plane, forming a floor to the lingual sinus, and extend dorsolaterally into the wall of the tongue (Plate IV(c)). These fibres insert indistinguishably amidst the distal fibres of the M. hyoglossus. Stimulation close to the base of the tongue extends its anterior end, but does not extensively protrude the tongue.

M. hyoglossus (Fig. 3(d)).-The M. hyoglossus ( $\mathrm{M}$ hyoglos) originates in two proximal heads-one from each of the posteromedial processes of the hyoid-that merge at the level of the posterior margin of the hyoid plate. Here, the M. hyoglossus lies immediately ventral to the hyoid plate; in cross section, its longitudinal fibres form one large, more or less homogeneous bundle. As they extend past the anteroventral margin of the hyoid plate, the fibres diverge posterodorsally and dorsolaterally over the edge of the hyoid to form the broad posterior margin of the tongue (Plate IV $(\mathrm{g})$ ). Anterior to this major delamination of the M. hyoglossus, two sets of longitudinal fibres form paired central, round bundles of muscle (Plate IV(d)-(f)). These bundles are in turn flanked laterally by broad, flattened bands of longitudinal fibres that underlie the base of the tongue along its sides. Fibres diverge dorsolaterally from along the length of these lateral bundles to form the sides of the tongue; other fibres diverge dorsally from along the medial bundles to form the top of the tongue. More 
anteriorly, the number of longitudinal fibres gradually diminishes. The delaminating fascicles form the sides and top of the tongue and terminate along the anterior surfaces of the tongue in an indistinguishable mixture with the terminal fascicles of the M. genioglossus. Stimulation of the several portions of the M. hyoglossus narrows the posterior end. When the muscle is stimulated uniformly, it causes extension of its anterior end.

M. sternohyoideus (Figs 3(b), (c)).-The robust $\mathrm{M}$. sternohyoideus ( $\mathrm{M}$ sternhyd) originates via two heads from the dorsal surfaces of the coracoid and clavicle, respectively, rather than from the sternum and external surface of the abdomen, as is usual in many other frogs. The posterior fibres extend to join those of the anterior head. The sternohyoid fibres pass deep to the $\mathrm{M}$. hyoglossus to insert on the hyoid plate rather than on the posteromedial process of the hyoid. The insertion covers the entire lateral portion of the hyoid plate in the position usually occupied by the $\mathrm{Mm}$. petrohyoideus anterior and $\mathrm{M}$. omohyoideus. Some anterior fibres insert along the ventrolateral margin of the anterior cornua of the hyoid. Stimulation of the M. sternohyoideus retracts the hyoid and the tongue upon it.

M. petrohyoideus (Fig. 3(c)).- Generally, the M. petrohyoideus is subdivided into two anterior (M. petrohyoideus anterior) and two posterior (M. petrohyoideus posterior) components. Each originates deep to the $\mathbf{M}$. depressor mandibulae from the ventral surface of the crista parotica. The anterior slip of the $M$. petrohyoideus anterior typically inserts on the ventral surface of the anterolateral process of the hyoid (antlat proc) and the margin of the hyoid plate deep to the M. geniohyoideus and lateral to the M. hyoglossus. Rhinophrynus lacks the anterior of the two slips of the M. petrohyoideus anterior; significantly, it also lacks an anterolateral hyoid process and the usual area of insertion for the $M$. petrohyoideus anterior is occupied by the $\mathrm{M}$. sternohyoideus. Fibres of the posterior part of the $M$. petrohyoideus anterior ( $M$ pethyd 1 ) extend posteroventrally and insert on the dorsal surface of the posterolateral process of the hyoid. Two parts of the M. petrohyoideus posterior are present. From their normal point of origin, the fibres of the two posterior heads extend posteroventrally to insert on (1) the dorsal surface of the posteromedial process (M pethyd 3), and (2) the ventral surface of the posteromedial process (M pethyd 2, lateral to the origin of the M. hyoglossus), respectively. Stimulation of the several heads of the petrohyoid induces retraction of the hyoid. If stimulation is unilateral, the hyoid is shifted toward that side.

M. omohyoideus.-As noted by Walker (1938), Rhinophrynus lacks the M. omohyoideus.

\section{Discussion \\ The habitus of Rhinophrynus}

Rhinophrynus are clearly subterranean animals. Their highly flexible bodies, coupled with short, stout hind limbs equipped with digging spades, allow them to dig backwards and to shift among clods of soil. When Rhinophrynus dig, they twist their bodies and change their inflation patterns to facilitate penetration of the substrate and, subsequently, the filling of the shaft above them with soil. (On the other hand, their capacity to inflate their body obviously would permit them to maintain the patency of a resting cavity until the disturbed sediments had a chance to consolidate.) While Rhinophrynus tend to dig backwards as they 
move from the surface into the soil, they would not use this mechanism in feeding in termitaria, which typically consist of an exceedingly tough outer shell of saliva-cemented soil that houses internal tunnel-like excavations or passageways (Michener \& Michener, 1951; Krishna \& Weesner, 1969-1970; Mill, 1982). Forward motion involves some scraping with the widely placed, spatulate forelimbs and tuberculate hands.

Actual penetration of an ant or termite tunnel probably is accomplished by the tip of the snout. Several of the modifications seen in this genus may be interpreted as facilitating such forward movement. Among these is the wedge-shaped, strongly reinforced skull and the short, stiff mandible. The application of forces to the snout are facilitated by the effective elimination of a neck owing to the anterior position of the pectoral girdle which, in this species, overlaps the skull (Plate I, Fig. 1). The squarish, foreshortened appearance of these animals also assures considerable leeway in the direction of force application at the snout; forces applied at one of the hind feet will drive the pointed snout toward the opposite side and facilitate penetration and widening of crevices.

The spiny epithelium of the calloused nose and mandibular tip probably are also associated with this pattern of force application. They can be thought of as friction-enhancing devices that allow shear stresses to be established in the layers of soil immediately in front of the nose, thereby inducing the rupture of tunnel walls within termitaria by more than mere application of compressive stress.

The complex, lateral closure of the buccal opening (Plate III(c), (d)), permits these animals to extend the anterior portion of the tongue without a wide gape. Thus, only the lingual tip need leave the mouth; it can slide forward through an anteriorly facing, tubular aperture. The large, lateral mandibular glands (Plate III(a), (b)) open on the sides of the face and along the edges of the lips, clearly facilitating their seal; their secretion may be involved secondarily in lubrication of buccal movements. Because the mechanics of lingual movements are complex, they are discussed separately in the next section. However, several other buccal and oesophageal specializations seem to be associated specifically with feeding on ants and termites. Among the more interesting of these are the grooves in the roof of the mouth and the leaflike infoldings of the oesophageal wall (Plate V), which may allow frogs to withstand the bites of soldier ants and termites with minimal trauma. Particularly the very narrow, nonvascular folds that radiate into the oesophagus presumably act first by providing the prey with confusing signals, negating its capacity to orient itself or to identify an escape route. Also, bites along the luminal edges of these folds should be relatively innocuous to the frog. Presumably the oesophageal cells are replaced at the cryptlike bases between the folds (it might be interesting to look for mitotic figures here) similar to those seen in the bases of crypts further down the alimentary canal.

Protection against such chemically enhanced cheliceral clamping can occur either by developing a resistant material that cannot be penetrated or by smothering the action of the chelicerae with tissues that can regenerate rapidly and insulate more sensitive portions. (One might establish the metaphoric comparison between the military strategies of a line of fortresses and of a defence in depth in which the enemy is allowed to penetrate the country and then enveloped from all sides.) A mechanism of armouring the oesophageal surface is likely to be disadvantageous to a relatively small predator such as Rhinophrynus; it would tend to inhibit oesophageal motility and occupy a significant amount of space. (However, this mechanism is used by large marine turtles in which the oesophagus is lined with overlapping, heavily keratinized oesophageal processes.) 


\section{Lingual protrusion}

The mechanism of tongue protrusion had to be extrapolated from the above-described morphological pattern and from the stimulation experiments. The accounts given of the individual muscles describe their actions when stimulation was at a level low enough and localized enough so that we are fairly certain that only fibres of the particular muscle were shortening. (Stimulation at higher levels and with electrodes that have more exposed surface area may cause the stimulus to spread so that multiple muscle fibres are activated simultaneously.) The protraction and retraction hypotheses presented below were tested also by simultaneous stimulation of two or more muscle groups and these confirm the pattern characterized here.

The fundamental pattern of tongue protrusion in Rhinophrynus apparently involves two events (Fig. 4) that need not be temporally sequential. The first event is a stiffening and

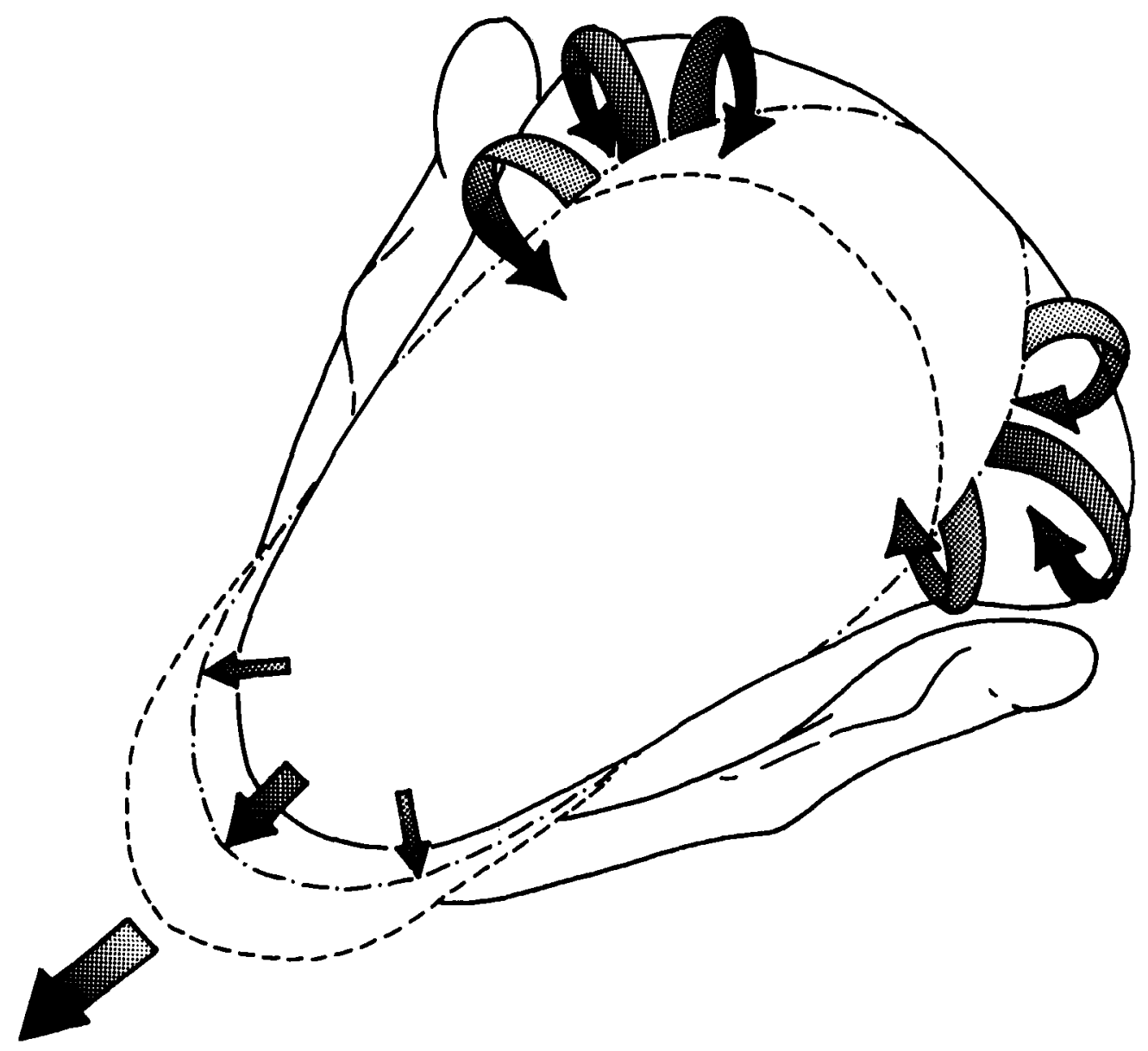

FIG. 4. Two-step mechanism of tongue protrusion in Rhinophrynus dorsalis. The resting position of the tongue is shown by a solid outline. The shape and position of the tongue on contraction of its intrinsic muscles is indicated by the dot-dash outline, and its fully protruded state by the dashed line. Shaded arrows represent the major directions of tongue movement and deformation. 
anterior extension of the tongue. This apparently is effected primarily by a contraction of the M. hyoglossus (rather than the M. genioglossus as in Rana and Bufo, Gans \& Gorniak, in press). The fibres of the $M$. hyoglossus radiate outward from the anterior edge of the hyoid plate; some extend to form the posterior wall of the tongue, others its sides and top. In general, more fibres per unit area insert on the posterior and posterolateral lingual walls than on the anterolateral and most anterior ones. Thus, contraction of the M. hyoglossus would seem to narrow the posterior portion of the triangular tongue, rounding this portion and displacing the lymph of the internal (but never patent) lingual sinus anteriorly to the zone where relatively few fibres provide resistance.

Action of the M. hyoglossus therefore squeezes the posterior portion of the tongue and causes its anterior part to be erected into a protruding, rodlike tube; this phenomenon was replicated a number of times when the muscle was stimulated. In contrast, contraction of the M. genioglossus inhibits forward protrusion of the lingual tip because this muscle gives off many fibres that insert into this tip. While it is facile to argue that action of the $\mathbf{M}$. hyoglossus is associated with stiffening and that of the M. genioglossus with relaxation, it may well be that some low-level contraction of the latter muscles occurs coincident with protrusion, so that the Mm. genioglossus and hyoglossus show modulated activity.

The second portion of lingual projection may not involve the glossal muscles at all. The hyoid plate and associated cornua of Rhinophrynus are unique in their substantial anteroposterior mobility (Trueb \& Cannatella, 1982). The hyoid of Rhinophrynus certainly differs from that of other frogs in providing a basal attachment for the tongue. Thus the action of the erecting $M$. hyoglossus is not only affected by its origin on the posteromedial processes of the hyoid but, more important, many of the fibres turn around the anterior edge of the hyoid plate. as around a sheave so that the posterior portions of the tongue are pulled together and protrude toward this. As the hyoid supports the rigidified tongue, movement or protrusion of the hyoid will protrude the tongue, forcing its turgid tip out of the mouth. The unique M. mandibulomentalis apparently may lift the buccal floor and facilitate this movement. The protrusion of the hyoid plate apparently occurs by action of the stout mass of the M. geniohyoideus (probably enhanced by action of the Mm. petrohyoidei). In this connection it is interesting to note that the insertions of two of the three slips of the M. petrohyoideus of Rhinophrynus seem to have shifted from the ventral to the dorsal portion of the hyoid plate. Thus, the extension of tongue in some ways resembles the positioning of an old-fashioned culverin on board a ship of war. The cannon (tongue) is first primed; only later is the gun carriage (hyoid plate) moved to protrude it through the gunport (buccal groove).

Retraction of the tongue occurs by means of the stout, anteroposteriorly directed sternohyoids. These muscles have a much larger area of insertion on the corpus of the hyoid plate (which is reinforced by a slim, transverse bone) than in other frogs (Trewavas, 1933; personal observation). In this connection, we also note the fact that the geniohyoid is single in Rhinophrynus and does not contain two discrete slips, the origins of which are separated from their posterior attach ment by the sternohyoid. Also the species lacks an omohyoid.

\section{Mechanics of the tongue}

How, then, does Rhinophrynus feed on termites? The lingual mechanism described represents an interesting subterranean foraging strategy well matched to prey operating at 
reasonable densities in isolated, fairly narrow tunnels in hard soil. Once the frog has uncovered such a tunnel by burrowing up to it and breaking its wall, it need only place the tip of its mouth against the aperture and extend the sticky tongue each time it detects a passing insect. (The tongue might even be left briefly in a position which occludes the tunnel and retracted only when a passing ant becomes involved with the sticky secretion.)

We visualize the tongue being stiffened and then protruded by the two-step mechanism described in the previous section. Because the sides of the mandibles are relatively stiff, we anticipate that contraction of the $\mathrm{Mm}$. submentalis and mandibulomentalis lifts the buccal floor, thus guiding the stiffened, protruding tongue above, rather than into, the symphysial region. The protrusion of the stiffened tongue would be directed by the groovelike vault of the buccal ceiling that is formed by the floor of the rostral projection. The relatively flexible and anteriorly directed buccal slit then would allow the tongue to protrude from the mouth through what amounts to a forward-facing tunnel; the sides of the "tunnel" remain closed by the overlapping lips, which provide further hermetic sealing by their copious glandular secretions.

Once prey has been enfolded by the cup-shaped, villous lingual tip, action of the sternohyoid would pull the tongue directly posteriorly. It is critical that the $\mathbf{M}$. hyoglossus remains active during this retraction period. Too early an inactivation would cause the tongue to become flacid, but not necessarily to retract it nor to retract the prey. Thus protrusion and retraction of the tongue of Rhinophrynus is very much a function of the muscles attaching the hyoid plate to the mandibular symphysis, the skull, and the pectoral girdle, respectively.

There are obviously several other complications to the system. One is the need for rapid cycling, probably before the first prey item has left the buccal cavity. Also, the tongue must be utilized for prey transport in the buccal cavity and toward the oesophagus. The grooves within the palatal roof well may be involved with this phase.

\section{Evolutionary implications}

The physical similarities between Rhinophrynus and various other tropical, subterranean species mentioned in the Introduction suggest convergence among diverse families on a specialized morphotype adapted to a burrowing mode of life. This habitus is characterized by a bulky body, usually with a dark ground colour with brilliant markings; short, stout limbs with well-developed palmar and plantar tubercles; and a short head with little or no apparent neck region. Despite these superficial similarities, detailed examination reveals that $R$ hinophrynus is a great deal more specialized than most other burrowing frogs. The mandible is positioned further forward in connection with the anterior elaboration of the snout (Trueb \& Cannatella, 1982). The snout is long and narrow, instead of blunt, and covered by a spiny integument that is absent in all other frogs. Most important, the tongue of Rhinophrynus has a Bauplan that is markedly different from that of all other frogs because contraction of the $\mathrm{Mm}$. genioglossus and hyoglossus only serves to stiffen the tongue, but not to protrude it. Protrusion is induced by a shift of the entire tongue via the hyoid base to which the tongue is attached. Thus, instead of having a "froglike" catapulting mechanism of tongue protrusion, the tongue of Rhinophrynus is protruded by means of continuous muscular control without any projectile component.

The occurrence of two such drastically different patterns of lingual propulsion among anurans raises an obvious question as to the possible existence of a more generalized, ancestral condition. On the one hand, there are the aglossal pipids to which Rhinophrynus is 
related most closely (Sokol, 1975, 1977). Had the two types of tongues arisen from an aglossal ancestor, the divergent lingual apparatuses would have to have evolved, de novo, on two separate occasions. Moreover, because the "tongueless" pipids retain both hyoid plates (albeit modified) and traces of tongue musculature (Chaine, 1901; Horton, 1982), they are not likely candidates for an ancestral "type". On the other hand, the structure of the tongue in Bombina (Discoglossidae) and Ascaphus (Leiopelmatidae) as illustrated by Regal \& Gans (1976: 723) seems a more reasonable ancestral condition. In these species, the tongue is little more than a loose folding of mucous tissues that enclose overlapping radiations of the genioglossal and hyoglossal fibre bundles in the buccal floor. Contraction of the fibres moves the entrained (extracellular) lymphatic fluids anteriorly; as a consequence, the mass of the tongue is allowed to bulge forward over the mandibular symphysis. From a functional viewpoint, it is not unreasonable to propose that the highly projectile tongues of most anurans and the "artillery-piece" tongue of Rhinophrynus might have evolved from this generalized sort of tongue and tongue-propulsion mechanism. Thus, in the case of most anurans that protrude their tongues by means of a lingual flip, the genioglossal mass hypertrophied and increased its capacity for intracellular stiffening, thereby producing the capacity for the "ballista mechanism", as described by Gans \& Gorniak (1982). In Rhinophrynus, in contrast, the hyoglossal mass hypertrophied and developed the capacity for hydrostatic stiffening utilizing extracellular fluids primarily. Given such an arrangement, the tongue would have to be moved by a second set of muscles; this could happen only if the tongue were connected firmly to the hyoid, so that movement of the hyoid would effect movement of the tongue.

One of the more startling results of this analysis is the realization that at least one frog moves its hyoid in order to move its tongue. In this respect, Rhinophrynus shows an obvious and general similarity to the patterns of tongue protrusion characterizing salamanders, chameleons, and various, less spectacular tongue-feeding lepidosaurs. However, it should be kept in mind that although the hyoid must move to shift the tongue in all of these animals, the detailed mechanisms of lingual activation and protrusion differ drastically, and therefore, are unrelated in an evolutionary context.

\section{Summary}

Morphological, cinematographic, and stimulation studies document that the Mexican burrowing toad, Rhinophrynus dorsalis, shows several specializations here interpreted as modifications for burrowing as well as for feeding on ants and termites. Its pointed rostrum bears keratinous spines, its pectoral girdle arches over the skull, and its oesophagus shows a unique pattern of folding. Its tongue utilizes a unique mechanism fundamentally distinct from that of other frogs. The muscles ( $\mathrm{Mm}$. genioglossus and hyoglossus) intrinsic to the tongue serve to stiffen it by acting on the fluid contents of the intrinsic lingual sinus. However, tongue protrusion and retraction, per se, involve the shift of the entire tongue on its mounting by means of the Mm. geniohyoideus, petrohyoideus, and sternohyoideus.

This work was supported in part by grants from NSF (DEB 80-03678 to C. Gans), DHEW (PHS-G 1R01DE05112 to C. Gans), and The University of Kansas Museum of Natural History (L. Trueb). We are grateful to Julian Lee who secured living specimens of Rhinophrynus dorsalis for our use, and to Sally Frost and John Simmons for the use of their photographic equipment and expertise in the preparation of photographs. 


\section{REFERENCES}

Chaine, J. (1901). Anatomie comparée de certains muscles sus-hyoidiens. Bull. Scient. Fr. Belg. 35: 1-210. (Thèse Fac. Sci. Paris (6 Dec. 1900). (A) 374 (1041): 1-210. L.)

Dugès, A. (1827). Recherches anatomiques et physiologiques sur la déglution dans les Reptiles. Annls sci. nat. 12: 337-395.

Freytag, G.E. (1967). Amphibia. In Urania Tierreich: Fische, Lurche, Kriechtiere. Leipzig, Jena, Berlin: UraniaVerlag.

Gans, C. \& Gorniak, G. (1982). Functional morphology of lingual protrusion in marine toads (Bufo marinus). Am. J. Anat. 163: 195-222.

Gaupp, E. (1896). A. Ecker' u. R. Wiedersheim's Anatomie des Frosches. 1, 2. Braunschweig: Friedrich Vieweg und Sohn.

Horton, P. (1982). The diversity and systematic significance of anuran tongue musculature. Copeia 1982: 595-602.

Kellogg, R. (1932). Mexican tailless amphibians in the United States National Museum. Bull. U.S. natn. Mus. No. 160: $1-224$.

Krishna, K. \& Weesner, F. M. (Eds) (1969-1970). Biology of termites. 2 Volumes. New York: Academic Press.

Lynch, J. D. (1973). The transition from archaic to advanced frogs. In Evolutionary biology of the anurans: Contemporary research on major problems: 133-182. Vial, J. L. (Ed.). Columbia: Univ. Missouri Press.

Magimel-Pelonnier, O. (1924). La lange des amphibiens. Thèse, Faculté des Sciences de Paris. A. Saugnac and E. Provillard, Bordeaux.

Michener, C. D. \& Michener, M. H. (1951). American social insects: A book about bees, ants, wasps, and termites. New York: D. Van Nostrand Company, Inc.

Mill, A. E. (1982). Amazon termite myths, legends and folklore of the Indians and Caboclos. Antenna (Bull. $R$. Ent. Soc. Lond) 6: 214-217.

Noble, G. K. (1931). The biology of the Amphibia. New York: McGraw-Hill Book Co.

Regal, P. J. \& Gans, C. (1976). Functional aspects of the evolution of frog tongues. Evolution 30: 718-734.

Sokol, O. M. (1975). The phylogeny of anuran larvae: a new look. Copeia 1975: 1-24.

Sokol, O. M. (1977). A subordinal classification of frogs. J. Zool., Lond. 182: 505-508.

Trewavas, E. (1933). The hyoid and larynx of the Anura. Phil. Trans. R. Soc. Lond. (B) 222: 401-527.

Trueb, L. \& Cannatella, D. C. (1982). The cranial osteology and hyolaryngeal apparatus of Rhinophrynus dorsalis (Anura: Rhinophrynidae) with comparisons to Recent pipid frogs. J. Morph. 171: 11-40.

Tyler, M. J. (1974). Superficial mandibular musculature of the Mexican Burrowing Toad, Rhinophrynus dorsalis. Herpetologica 30: 313-316.

Walker, C. F. (1938). The structure and systematic relationships of the genus Rhinophrynus. Occ. Pap. Mus. Zool. Univ. Mich. No. 372: 1-11. 